\title{
Developments in Processing of Functionally Gradient Metals and Metal-Ceramic Composites: A Review
}

\author{
T. P. D. Rajan • B. C. Pai
}

Received: 17 May 2014/Revised: 17 July 2014/Published online: 1 October 2014

(C) The Chinese Society for Metals and Springer-Verlag Berlin Heidelberg 2014

\begin{abstract}
Functionally gradient/graded materials (FGMs), an emerging new class of materials, are the outcome of the recent innovative concepts in materials technology. FGMs are in their early stages of evolution and expected to have a strong impact on the design and development of new components and structures with better performance. FGMs exhibit gradual transitions in the microstructure and/or the composition in a specific direction, the presence of which leads to variation in the functional performance within a part. The presence of gradual transitions in material composition in FGMs can reduce or eliminate the deleterious stress concentrations and result in a wide gradation of physical and/or chemical properties within the material. Functionally graded metal-ceramic composites are also getting the attention of the researchers. Among the fabrication routes for FGMs such as chemical vapour deposition, physical vapour deposition, the sol-gel technique, plasma spraying, molten metal infiltration, self propagating high temperature synthesis, spray forming, centrifugal casting, etc., the ones based on solidification route are preferred for FGMs because of their economics and capability to make large size products. The present paper discusses and compares various solidification processing techniques available for the fabrication of functionally gradient metals and metal-ceramic composites and lists their properties and possible applications. The other processing methods are briefly described.
\end{abstract}

KEY WORDS: Functionally gradient materials; Solidification; Aluminium; Centrifugal casting; Infiltration

\section{Introduction}

Developments in science and technology rely heavily upon the development of new material systems that can withstand the conditions created by advancing technology. Functionally graded materials (FGMs) hold the key for applications requiring ultra-high material performance such as thermal barrier coatings, bone and dental implants, piezoelectric and thermoelectric devices, optical materials with graded

Available online at http://link.springer.com/journal/40195

T. P. D. Rajan · B. C. Pai ( $\square)$

Materials Science and Technology Division, CSIR - National

Institute for Interdisciplinary Science and Technology, Industrial

Estate PO, Trivandrum 695019, India

e-mail: bcpai12@rediffmail.com refractive indices etc. Moreover, new applications are continuously being discovered. FGMs are generally two-component composites characterised by a compositional gradient from one component to the other. Finite transitions in materials extend from one material or phase to another necessarily comprising an intermediate region which is a composite of the two, if they are not fully miscible. Therefore, the vast majority of graded structures are mostly made of composites or multiphase materials. Figure 1 shows the schematic illustration of FGMCC microstructure. In contrast, traditional composites are homogeneous mixtures, leading to a compromise between the desirable properties of the component materials. Since significant proportions of an FGM contain the pure form of each component, the need for compromise is eliminated. The properties of both the components can be fully utilised. For example, the toughness of a metal can be mated with the refractoriness of a ceramic, 


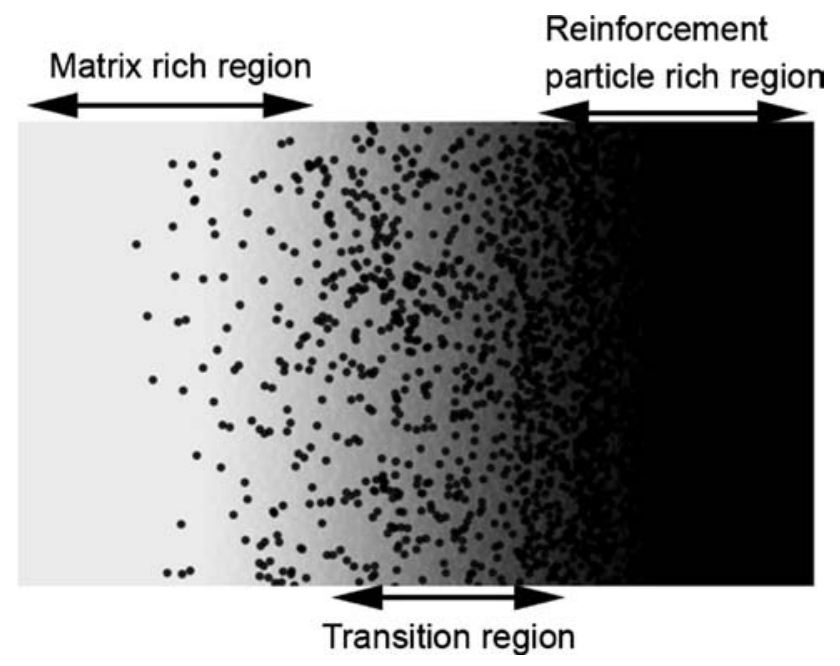

Fig. 1 Schematic illustration of an FGMCC with continuously graded microstructure

without any compromise in the toughness of the former or the refractoriness of the latter.

The FGM concept originated in Japan in 1984 during the spaceplane project, in the form of a proposed thermal barrier material capable of withstanding a surface temperature of 2,000 K and a temperature gradient of 1,000 K across a cross section $<10 \mathrm{~mm}$. However, the gradient materials are not new; since they exist in the nature (the Earth itself is graded). The man has extensively utilised either natural or processed materials containing microstructural gradients. For example, both heat and mass diffusion techniques have been used for centuries to create functional, microstructural and/or compositional gradients in steel. The new aspect of FGMs is the realisation of graded properties by designing at the microstructural level to tailor materials, mostly composite systems for the specific functional and performance requirements of an intended application. With the advent of these new processes and materials, one can envision the development of a novel approach to the fabrication of components for demanding applications, which has been termed "inverse design procedure" [1]. Here, component design and fabrication are based not on a list of existing materials, but on a choice of available basic material ingredients and material processes, combined with three-dimensional mechanical analysis of graded structures. These two engineering disciplines are thus combined to design synergistically both the components and their processing. Mortensen and Suresh $[2,3]$ have presented excellent reviews on the FGM concept, structure and themo-mechanical properties earlier, and recently Sobczak and Drenchev [4] have presented a detailed review on metal bases FGMs. The present paper discusses and compares the various solidification processing techniques available for the fabrication of functionally gradient metals and metal-ceramic composites and presents their properties and possible applications. The other processing methods are briefly described. The paper also emphasises various FGM systems fabricated by the authors through solidification processing technique.

\section{Processing Methods}

Since a wide variety of processing methods are available for the fabrication of functionally graded metal-ceramic composites, it is difficult to group them. Mortensen and Suresh have classified the processing methods of FGMs broadly as constructive and transport-based processes [2]. In the constructive processes, the FGMs or the precursors such as preforms are constructed layer by layer with appropriate gradients in the distribution of constituent phases. On the other hand, the transport-based processes create the gradients in local microstructure and/or composition in a component by the natural transport phenomena such as the flow of fluid, the diffusion of atomic species or by heat conduction. In the case of FGMCC, the processing methods can be broadly classified as solid state processes, liquid states processes and vapour state/deposition processes, depending on the nature of processing.

In liquid state processes, the matrix is either fully or partially molten during the formation of FGMCC. The important methods in liquid state processing are infiltration, gravity-aided settling and centrifugal casting. In solid state processes, the constituents of FGMCC, both the matrix and the reinforcements, are usually in the solid state during their processing. The powder metallurgy and diffusion bonding are the important solid state processes. In deposition processes, the graded and the outer layers are deposited on a prefabricated bulk component. These processes are very attractive and find wide applications due to the formation of functionally graded layers between a bulk component and the outer coating which protects the components from the harsh conditions such as temperature, corrosion or erosion.

Among the various fabrication techniques mentioned above, important solidification processing methods are infiltration, settling, centrifugal casting, spray casting and laser melt processing, which are described below.

\section{Solidification Processes}

\subsection{Infiltration}

Infiltration process involves the preparation of graded ceramic preform containing graded porosity and its 

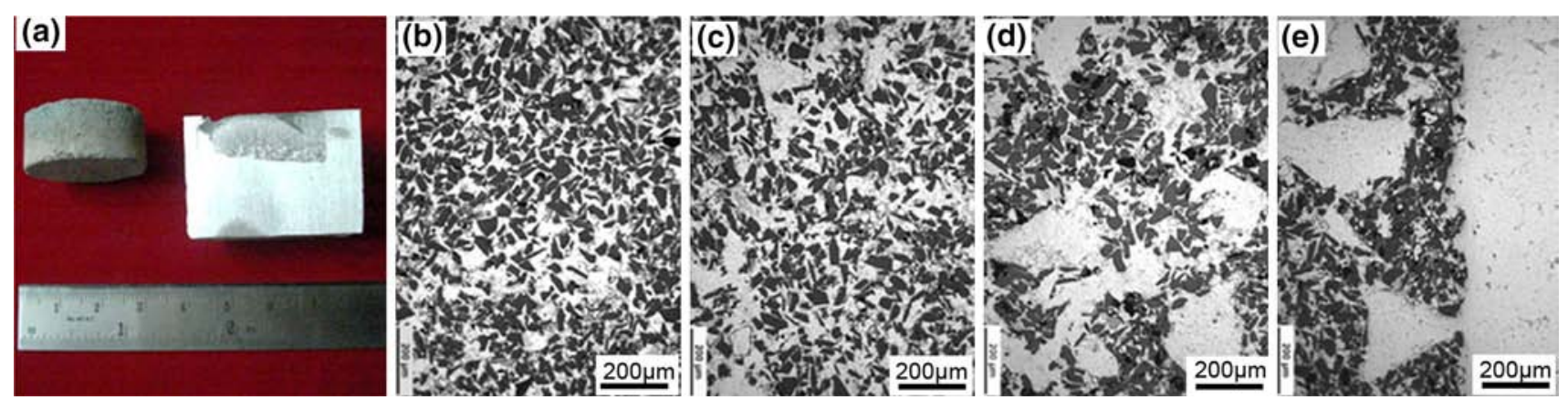

Fig. 2 a Graded $\mathrm{SiC}$ perform and aluminium-SiC infiltrated specimen, b-e microstructures of functionally graded $\mathrm{Al}(6061)-\mathrm{SiC} \mathrm{p}_{\mathrm{p}}$ composite by squeeze infiltration

infiltration with the liquid metal with or without the application of pressure or vacuum. Al FGMCC for automotive applications has been successfully fabricated, featuring graded transition from aluminium to ceramicreinforced aluminium at surfaces. One of the critical steps involved in this process is the fabrication of the preform with the required concentration of the particles. For making perform with uniform porosity conventional binder and slurry method is one of the common methods. The reinforcements especially the short fibres are mixed homogenously with water accompanied with small addition of the binder. The water is drained off later to make the preform. The typical method used for the preparation of graded perform consists of preparation of the slurries with different concentrations of the reinforcements and then stacking them to get the required reinforcement gradients. Graded preform should have sufficient porosity for the liquid metal to penetrate and to get solidified. In the case of higher volume fraction, preform should not experience excessive deformation during pressure-assisted infiltration of metal [5]. Figure 2a shows the aluminium-SiC composite prepared using a graded porous $\mathrm{SiC}$ preform and by squeeze infiltration technique, and Fig. 2b-e show the microstructures of the composite region.

Aluminium pistons locally reinforced along their crown surface have been produced using preforms containing four layers of distinct fraction of $21,25,40$ and $51 \mathrm{vol} \%$ of hybrid reinforcements of alumina short fibres and aluminium titanate particles, which are created by conventional slurry and binder methods [6]. These graded composites have shown superior thermal crack resisting performance, compared with corresponding unreinforced and ungraded MMC pistons. Corbin et al. [7] have synthesised functionally graded $\mathrm{Al}-\mathrm{Mg} / \mathrm{ZrO}_{2}$ components by spontaneous infiltration of $\mathrm{ZrO}_{2}$ preforms with a graded porous structure in $\mathrm{N}_{2}$ atmosphere. The infiltration processes have the versatility of using particles and wide range of fibres with low and high volume fractions for the preparation of functionally graded materials.
W-Cu FGM was prepared by high-gravity combustion synthesis and melt-infiltration technique. The high gravity was achieved by centrifugal rotation. The $\mathrm{W}$-rich layer shows both better strength and plasticity than the commercial $\mathrm{W}-\mathrm{Cu}$ composite with a similar composition prepared by a conventional infiltration method [8].

\subsection{Settling}

In this process, the MMCs are fabricated by the liquid metal stir casting and allowed to separate into fully matrix liquid metal and graded ceramic reinforced MMC by holding the slurry in the gravity. Al-SiC graded composites by gravity settling are produced in various experimental components [9]. The primary limitation of this process in the context of FGM production is its tendency to produce separate zones of relatively constant volume fraction. This limitation can be overcome using a range of particle sizes. The larger particles settle faster than smaller particles due to their higher terminal velocity. The aspect ratios of the reinforcements also affect the settling conditions. Lajoye and Suery $[10,11]$ have suggested a method of sequential pouring of slurries of controlled and variable particle volume fractions.

Hanumanth et al. [12] studied the sedimentation behaviour of high volume fraction (as high as 0.30) of $90-\mu \mathrm{m}$-diameter $\mathrm{SiC}$ particles in liquid aluminium using an electrical resistance probe to measure the in situ particle volume fraction. A multiphase hydrodynamic model was developed to describe the sedimentation. Using the same resistance probe, settling and clustering of $14-\mu \mathrm{m} \mathrm{SiC}$ particles in $\mathrm{Al}$ melts were monitored and analysed by Irons and Owusu-Boahen [13]. The observed settling rate was consistent with that of $38 \mu \mathrm{m}$ clusters containing $42 \mathrm{vol} \%$ particles within the clusters. It was concluded that intense stirring prior to settling would result in smaller clusters.

The remelting and sedimentation $(\mathrm{R} \& \mathrm{~S})$ process was used to produce a functionally graded $\mathrm{Al} / \mathrm{SiC}$ composite with a smooth concentration gradient of $\mathrm{SiC}$ particles along 


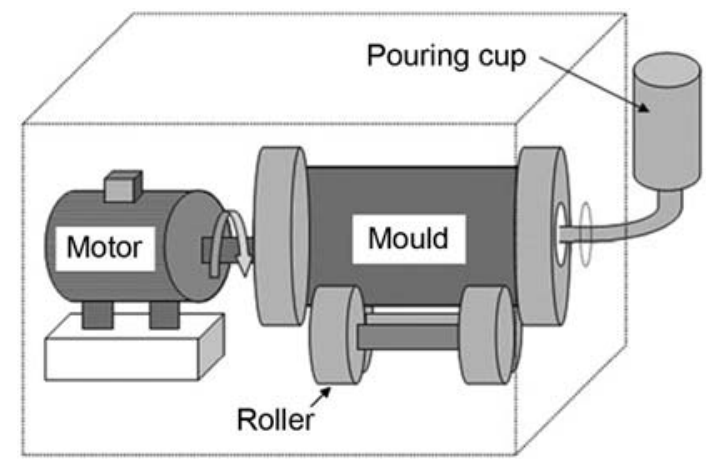

Fig. 3 Schematic diagram of horizontal centrifugal casting process for FGMCC

the height of samples, as opposed to a step change. The settling velocities were measured for different-sized $\mathrm{SiC}$ particles in A356 aluminium alloy. The slices of $\mathrm{Al} / \mathrm{SiC}$ composites with different $\mathrm{SiC}$ contents of 5, 10, 15 and 20 vol\% were stacked in a cast iron mould and heated at $650{ }^{\circ} \mathrm{C}$ resulting in remelting and unification of the different composite parts providing a smooth gradient of $\mathrm{SiC}$ concentration along the height of the sample [14].

\subsection{Centrifugal Casting}

Centrifugal casting is the most sought process for making functionally graded components. The centrifugally cast spun pipes exhibited dense structure near the outer periphery, and columnar grains are radially oriented giving superior strength, fracture toughness and improved corrosion resistance properties. Segregation of the alloying elements due to the centrifugal action was also found to be responsible for the changes in the morphology and structure of the grains. Similarly, centrifugally cast steel-backed babbit bearings have shown better bonding with superior properties. In general, in single phase alloy systems, compared to gravity castings centrifugal casting [15], it gives much superior properties depending on the system and solidification conditions. In two or multi phase alloys during the centrifugal casting depending on the density of the phases graded separations will take place upon solidification. For MMC products, centrifugal casting involves the synthesis of MMCs by stir casting method followed by the formation of gradients in microstructure by the application of centrifugal force. Figure 3 shows the schematic diagram for the manufacturing of FGMCC by horizontal centrifugal casting method [16]. Effects of processing condition on the structure and properties of the composites have been well studied for both vertical and horizontal centrifugal casting processes [17]. The limitation of the centrifugal casting is that it is only suitable for axial

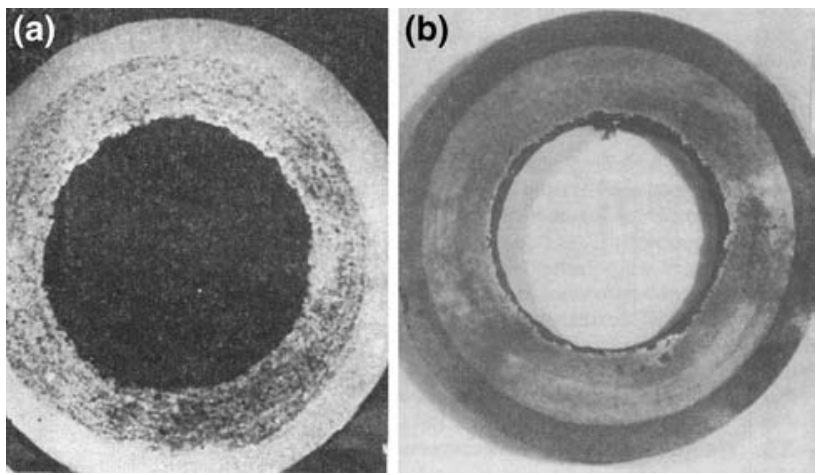

Fig. 4 Centrifugal casting of Al-graphite and Al-zircon composites $[18,19]$

symmetry components giving gradient structure in the radial direction.

When particle-containing slurry is subjected to centrifugal force, two distinct zones of particle enriched and depleted are formed. The extent of particle segregation and relative locations of enriched and depleted particles zones within the casting are mainly dictated by the melt temperature, metal viscosity, cooling rate, the densities of the particle and liquid, particle size and magnitude of centrifugal acceleration. Depending on the density of particles, the lighter particles segregate towards the axis of rotation, while the denser particles move away from the axis of rotation. In the case of aluminium alloys, the particleenriched zone of the heavier particles such as $\mathrm{SiC}$, alumina and zircon are at the outer periphery and the lighter particles such as graphite, mica and microbalance of carbon are at the inner periphery of horizontally spun cylindrical centrifugal castings. The thickness of particle-enriched zone decrease with the increasing pouring temperature and speed of rotation. Figure 4 shows the segregation of graphite and zircon particles towards the inner and outer periphery of the centrifugal castings, respectively $[18,19]$.

When solidification accompanies centrifuging, the segregation of particles due to particle movement is slowed down as a result of decreasing melt temperatures during cooling and crowding of particles occurring in progressively narrow zones. Velhinho et al. [20] have produced a functionally graded $\mathrm{SiC}_{\mathrm{p}}$-reinforced aluminium-matrix composites by centrifugal casting and observed that as a consequence of centrifugal casting, $\mathrm{SiC}$ particles are partially clustered, with some pores due to imperfect wetting of ceramic particles by the molten aluminium alloy. The entrapped gases in the molten composite melts will have the tendency to get attached with the un-wetted or partially wetted reinforcements and the virtual density of the agglomerate being much lower than the reinforcements, resulting in higher concentrations of clusters in the inner 
Table 1 Observations made on centrifugal casting of different aluminium metal matrix composites

\begin{tabular}{|c|c|}
\hline Composite system & Observations \\
\hline \multirow[t]{3}{*}{$\mathrm{Al}-\mathrm{SiC}$ [22-24] } & $\begin{array}{l}\text { Graded distribution of } \mathrm{SiC} \text { particles near the } \\
\text { outer periphery of the casting }\end{array}$ \\
\hline & $\begin{array}{l}\text { Higher strength and modulus near outer } \\
\text { periphery }\end{array}$ \\
\hline & $\begin{array}{l}\text { A smooth and gradual distribution of particles is } \\
\text { observed when mixture of particle sizes is } \\
\text { used }\end{array}$ \\
\hline Al-graphite [18] & $\begin{array}{l}\text { Higher volume fraction of graphite particles } \\
\text { near the inner periphery of the casting }\end{array}$ \\
\hline $\mathrm{Al}-\mathrm{Si}$ & $\begin{array}{l}\text { Primary Si particles are observed near the inner } \\
\text { periphery of the hollow casting }\end{array}$ \\
\hline \multirow[t]{3}{*}{$\mathrm{Al}-\mathrm{Al}_{3} \mathrm{Ni}[25,26]$} & $\begin{array}{l}\text { Primary } \mathrm{Al}_{3} \mathrm{Ni} \text { phases near the inner periphery } \\
\text { of the casting }\end{array}$ \\
\hline & $\begin{array}{l}\text { Al- } 20 \% \mathrm{Ni} \text { forms the best graded distribution } \\
\text { compared to } \mathrm{Al}-(10-40 \%) \mathrm{Ni}\end{array}$ \\
\hline & $\begin{array}{l}\text { Young's modulus vary from } 81 \text { to } 100 \mathrm{GPa} \\
\text { across the } 6 \text {-mm tube wall thickness from the } \\
\text { inner to outer surface, reflecting } 15.2 \text { and } \\
43.2 \text { vol\% } \mathrm{Al}_{3} \mathrm{Ni} \text { second phase }\end{array}$ \\
\hline $\mathrm{Al}-\mathrm{Al}_{2} \mathrm{Cu}[27]$ & $\begin{array}{l}\text { Graded structure of } \mathrm{Al}_{2} \mathrm{Cu} \text { is observed in } \mathrm{Al}- \\
33 \text { mass } \% \mathrm{Cu} \text { eutectic system }\end{array}$ \\
\hline $\mathrm{Al}-\mathrm{Al}_{3} \mathrm{Ti}[28,29]$ & $\begin{array}{l}\mathrm{Al}_{3} \mathrm{Ti} \text { platelets are distributed gradually near the } \\
\text { outer periphery of cylindrical casting }\end{array}$ \\
\hline $\mathrm{Al}-\mathrm{AlB}_{2}[30]$ & $\begin{array}{l}\mathrm{AlB}_{2} \text { particles with higher bulk density than } \\
\text { liquid aluminium segregate towards the outer } \\
\text { surface regions leading to higher wear } \\
\text { resistance }\end{array}$ \\
\hline Al-SiC-graphite & $\begin{array}{l}\text { Graded distribution of } \mathrm{SiC} \text { and graphite } \\
\text { particles near the inner periphery of the } \\
\text { casting. Few percentage of } \mathrm{SiC} \text { is also } \\
\text { observed near outer periphery }\end{array}$ \\
\hline $\begin{array}{l}\mathrm{Al}- \\
\qquad\left(\mathrm{Al}_{3} \mathrm{Ti}+\mathrm{Al}_{3} \mathrm{Ni}\right) \\
{[31]}\end{array}$ & $\begin{array}{l}\text { Hybrid } \mathrm{Al}-\left(\mathrm{Al}_{3} \mathrm{Ti}+\mathrm{Al}_{3} \mathrm{Ni}\right) \text { show superior } \\
\text { wear resistance than pure } \mathrm{Al} \text {. The wear } \\
\text { resistance at outer region of ring is higher } \\
\text { compare to inner region }\end{array}$ \\
\hline
\end{tabular}

periphery of the components with higher concentration of the gas porosities. Hence, proper wetting of particles with the matrix is necessary to reduce the clustering of particles. Functionally gradient $\mathrm{Al}(\mathrm{A} 359) / \mathrm{SiC}_{\mathrm{p}}$ composites have been fabricated by centrifugal casting by Rodríguez et al. [21] and it is observed that the $\mathrm{SiC}$ distributions along the thickness of the composite centrifugal castings at 1,300 and $700 \mathrm{r} / \mathrm{min}$ vary smoothly throughout the reinforced region, with a decreasing $\mathrm{SiC}$ volume fraction as a function of position giving the functionally graded microstructure. AlSiC FGMCC fishing boat cable pulleys are fabricated successfully by centrifugal casting method.

Table 1 lists the observations made on centrifugal casting of different MMC systems [22-31]. Figure 5 shows the optical microstructures of the vertical centrifugal cast $\mathrm{Al}(6061)-\mathrm{SiC}$ FGM. The experimentally measured volume fractions with respect to the distance of $\mathrm{Al}(6061)-\mathrm{SiC}$ functionally graded MMCs are depicted in Fig. 6. The distribution of $\mathrm{SiC}$ particle is rich near the outer periphery as observed from the microstructure. The distribution of $\mathrm{SiC}$ reduces gradually from a maximum $41 \mathrm{vol} \%$ near the outer periphery to $39 \mathrm{vol} \%$ at $2.5 \mathrm{~mm}, 35 \mathrm{vol} \%$ at $3.5 \mathrm{~mm}$, $24 \mathrm{vol} \%$ at $4.5 \mathrm{~mm}$ and $15 \mathrm{vol} \%$ at $5 \mathrm{~mm}$. At $6 \mathrm{~mm}$, there is no $\mathrm{SiC}$ particles and it is purely the $\mathrm{Al}(6061)$ matrix alloy [23]. When a mixture of varying particle sizes [14, 23 and $42 \mu \mathrm{m}$ average particle sizes (APS)] of equal proportion is used for making $\mathrm{Al}(356)-\mathrm{SiC}$ FGM, a smooth and gradual distribution of particles is observed, whereas in Al(356)-SiC FGM made by single-size particles ( $23 \mu \mathrm{m}$ APS) a sharp gradation is observed [24].

In $\mathrm{Al}-20$ vol\% silicon FGM fabricated by vertical centrifugal casting method (Fig. 7), the primary silicon particles formed are segregated as a graded layer in the inner periphery of casting leading to better hardness and improved wear resistance. The size and fraction of primary $\mathrm{Si}$ decreases towards the outer periphery reaching $0 \mathrm{vol} \%$ at about $25 \%$ of the length from the inner periphery.

Figure 8 shows the typical microstructures of $\mathrm{Al}-\mathrm{Al}_{3} \mathrm{Ni}$ functionally graded MMC formed from $\mathrm{Al}-20 \mathrm{wt} \% \mathrm{Ni}$ alloy from the outer to the inner periphery of the centrifugally cast hollow cylindrical casting [25]. The region near the outer periphery (Fig. 8a, b) is rich in Al3Ni primary crystals, whose concentration decreases towards the inner periphery (Fig. 8c, d). The transition from a hypereutectic microstructure to a near eutectic or hypoeutectic one takes place at about $10 \mathrm{~mm}$ from the outer periphery. The region near the outer periphery (Fig. 8a, b) shows both acicular and equiaxed primary $\mathrm{Al}_{3} \mathrm{Ni}$ phases, while the region near the inner periphery shows very fine eutectic phase.

The microstructural observation of vertical centrifugal cast LM 25-10\% SiC-5\% graphite FGM hollow cylinder (Fig. 9) shows that the distribution of a part of $\mathrm{SiC}$ in the outer periphery of the casting and the other part in the inner periphery along with the graphite particles leading to a hybrid functionally graded composite. The hindered settling phenomenon is responsible for the segregation of hybrid particles to the inner periphery of the castings.

Hypereutectic $\mathrm{Al}-\mathrm{Mg}_{2} \mathrm{Si}$ alloy tubes with graded distribution of the primary $\mathrm{Mg}_{2} \mathrm{Si}$ particles were produced by centrifugal casting [32]. Influence of rotation speed of the centrifugal mould and cooling rate during casting was investigated. Lower rotation speed resulted in better gradient distribution of $\mathrm{Mg}_{2} \mathrm{Si}$ primary particles accompanied with higher volume fraction of the casting defects. With an increase in rotation speed, an apparent change of the particle distribution profile in the outer periphery can be observed. Meanwhile, the influence of rotation speed on the particle distribution in the inner periphery is rather small. The extremely high cooling rate achieved using a 

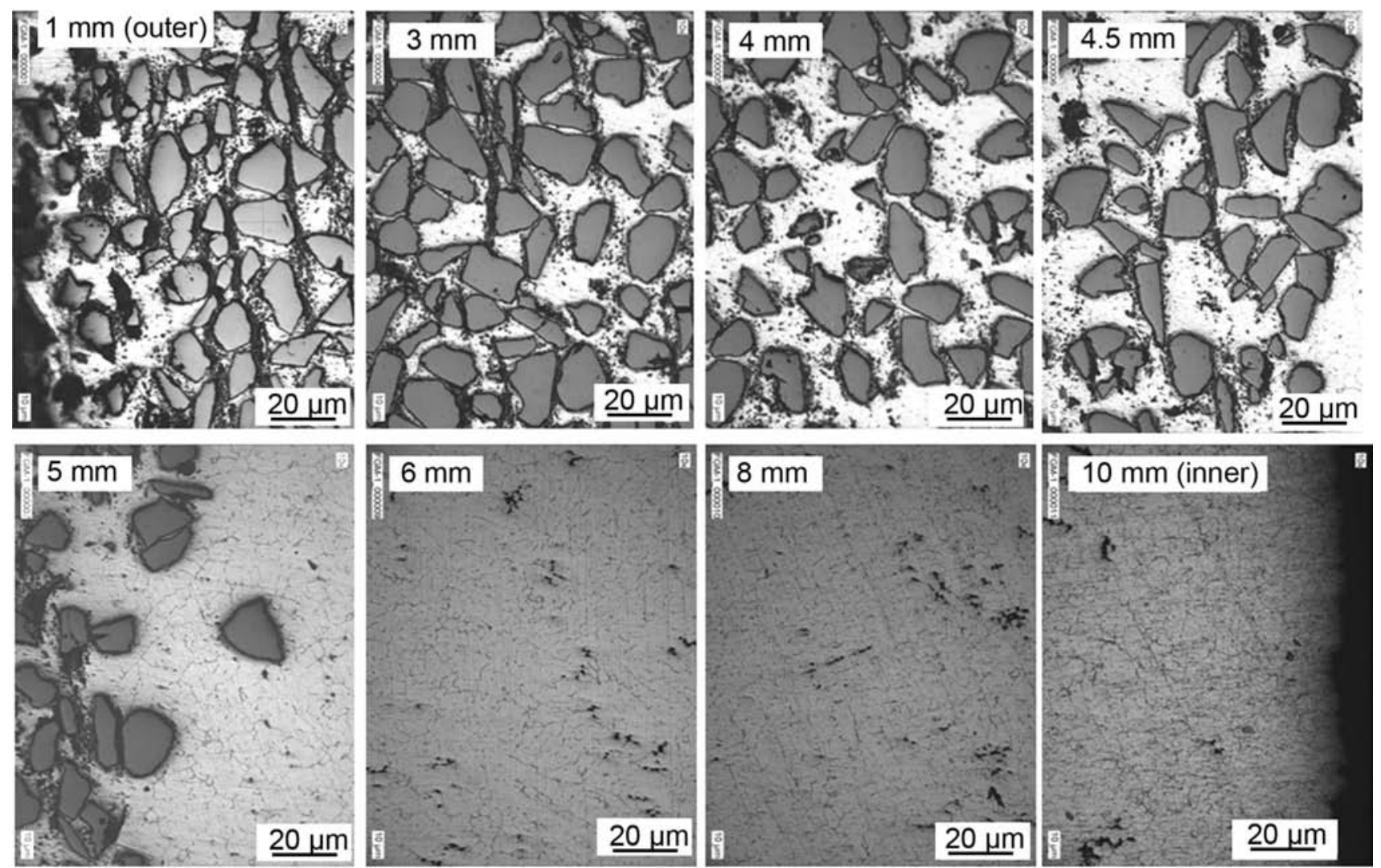

Fig. 5 Optical photomicrographs of $\mathrm{Al}(6061)-\mathrm{SiC}$ FGM at different positions

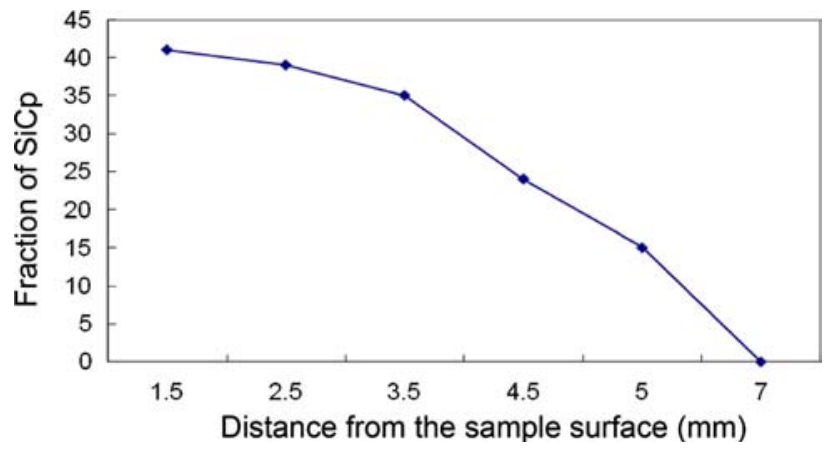

Fig. $6 \mathrm{SiC}$ Particle distribution in $\mathrm{Al}(6061)-\mathrm{SiC}$ FGM

copper mould with water cooling leads to a very fine microstructure in the outer periphery when compared with the same area in the other tubes obtained using graphite mould. Hence, both the microstructure and the macro segregation in the centrifugal tubes are tailorable.

Selectively reinforced casting (SRC), is a process developed by the Pacific Northwest National Laboratory on the basis of centrifugal casting method to produce inhomogenously reinforced/FGM components from stir-cast particulate MMCs [33]. The process uses the radial forces generated from centrifugal casting to segregate a second discrete phase from the matrix of MMCs. Selectively
Reinforced Casting can produce parts with a high density of particles in the reinforced region. Reinforcement density can reach levels more than 50 vol\%, with starting feedstock levels of only $10 \mathrm{vol} \%$. This can reduce the material cost of a MMC component, by minimising the amount of costly reinforcement phase needed in the feedstock material.

The ability to produce and tailor a gradient in the reinforcement distribution hinges first on an understanding of the migration of the particles in the melt before solidification. Lajoye and Suery [11] modelled this process in the context of centrifugal casting. They considered the trajectory of a solid particle in the liquid over the duration of the process, from the moment it enters the segregative force field to the moment it is trapped in place by the moving solidification front. The process thus combines modelling of solidification in the casting, and a calculation of the time-dependent particle distribution by integration of the trajectories of all particles present.

\subsection{Sequential Casting/Controlled Mould Filling}

Sequential Casting leads to formation of FGM systems by controlled mould filling of molten metal, alloys or composites in sequential method. The challenges during 

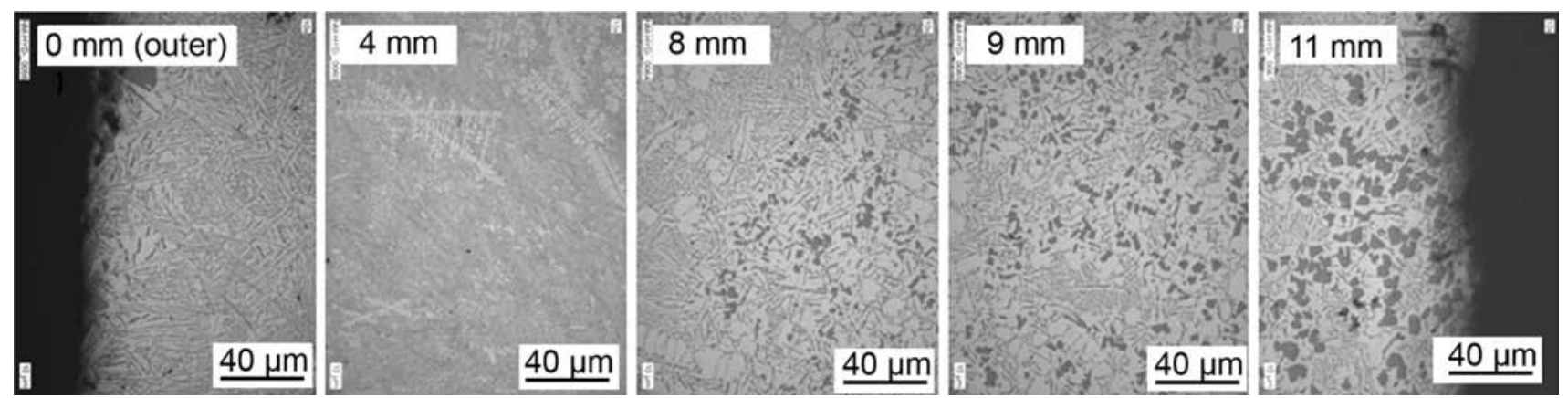

Fig. 7 Optical micrographs of Al-20\% Si FGM fabricated by vertical centrifugal casting
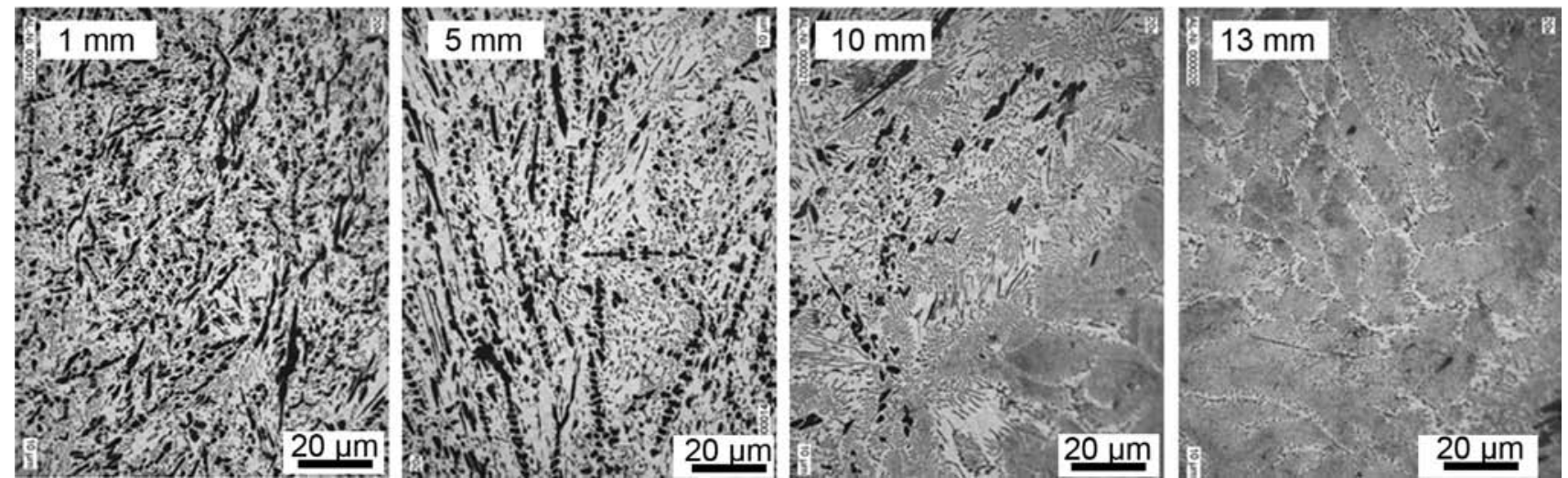

Fig. 8 Optical micrographs of $\mathrm{Al}-\mathrm{Al}_{3} \mathrm{Ni}$ in situ functionally graded composite formed from outer periphery of the casting $\mathrm{Al}-20 \% \mathrm{Ni}$
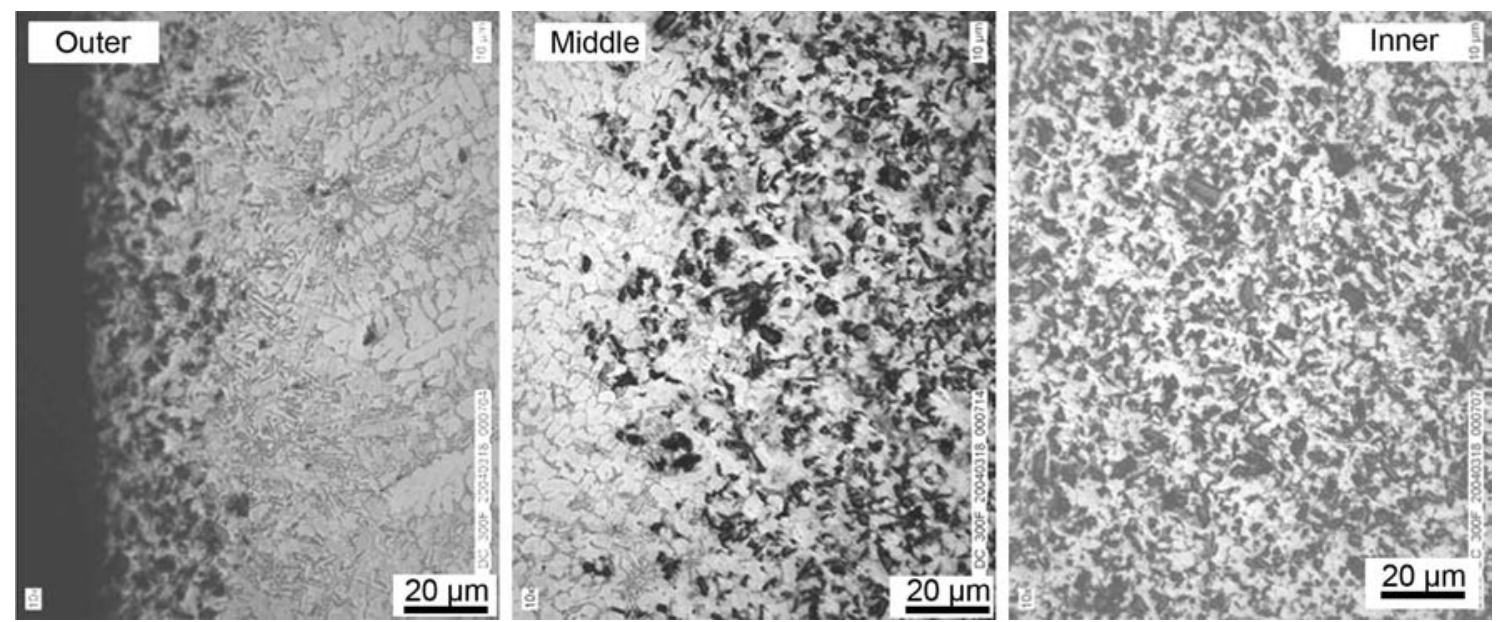

Fig. 9 Optical micrographs of $\mathrm{Al}-10 \mathrm{SiC}-5$ graphite functionally graded metal matrix composites by centrifugal casting from outer to inner periphery

processing FGMs by sequential casting are poor adhesion between the layers if the processing parameters such as pouring temperature, time and sequence are not maintained properly. Figure 10 shows the microstructure of sequentially cast aluminium alloys showing the debonding of the layers. Figures 11 and 12 show the sequential gravity and centrifugally cast Al319 and Al390 aluminium alloys with good bonding. The sequential cast is one of the most economical casting techniques for making functionally graded component. Studies have shown the sequentially 


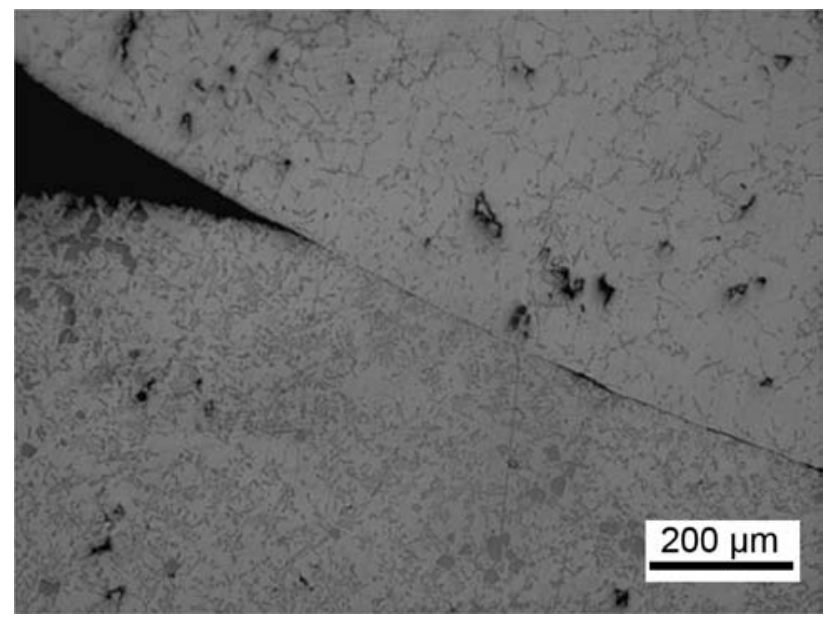

Fig. 10 Microstructure of sequentially cast aluminium alloys showing the dewetting of the layers gravity cast A319 and A390 aluminium alloy shows the hardness values of $70 \mathrm{BHN}$ in $\mathrm{A} 319$ region and $130 \mathrm{BHN}$ in $\mathrm{A} 390 \mathrm{Al}$ alloy region.

\subsection{Spray Casting}

Spray casting, also known as spray forming or spray deposition is the inert gas atomization of a liquid metal stream into various-sized droplets which are then propelled away from the region of atomization by the fast flowing atomizing gas. The droplet trajectories are interrupted by a substrate for collection and solidification into a coherent near fully dense perform [34]. The particle-reinforced composites are generally made by injecting the solid reinforcing particles directly into the matrix alloy spray, followed by deposition of the mixture into a substrate. In the case of FGMCC formation, the particle injection rate
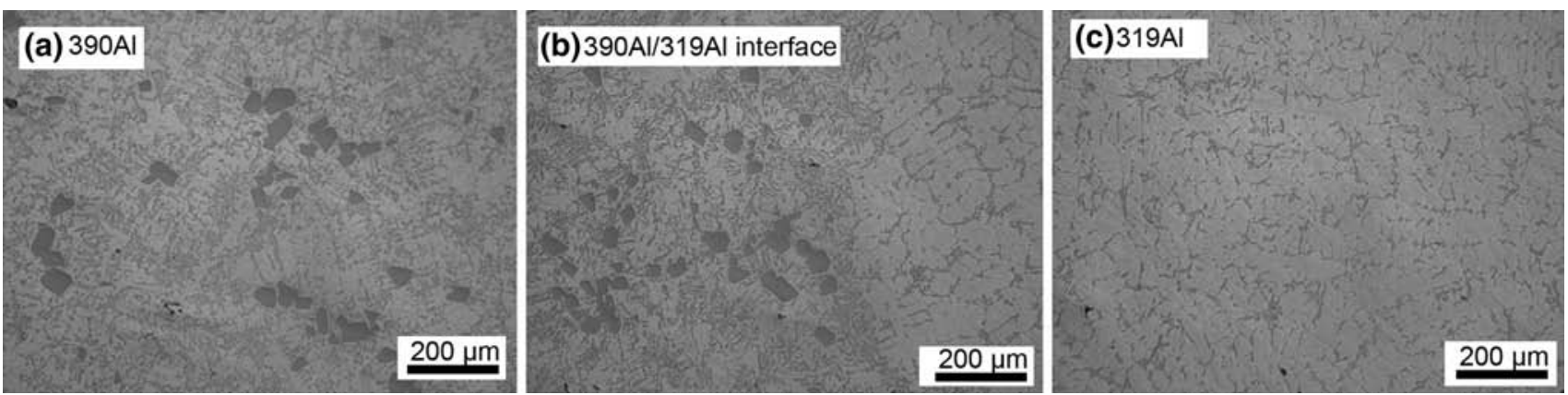

Fig. 11 Microstructures of the sequential gravity Al319 and Al390 aluminium alloys with good bonding
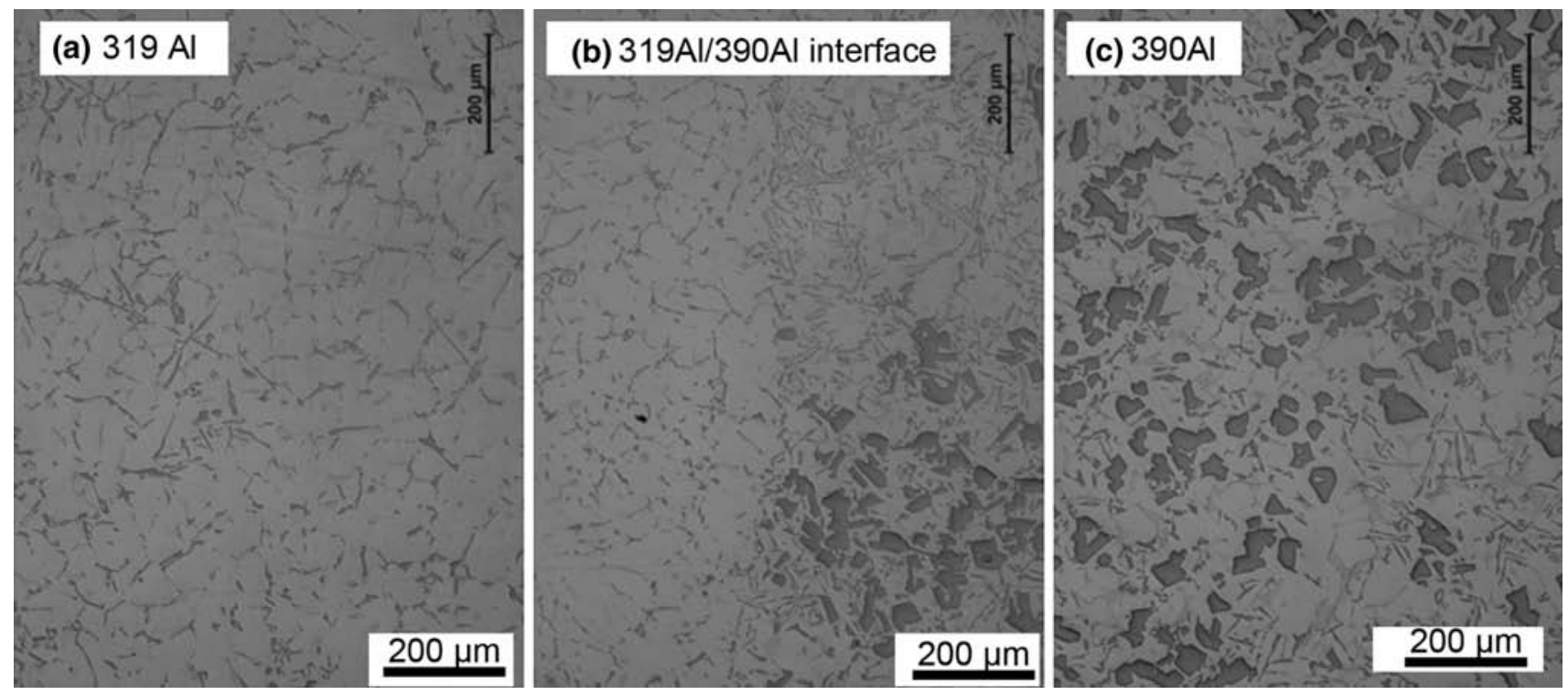

Fig. 12 Microstructures of the sequential centrifugally cast A1319 and Al390 aluminium alloys 
into the metal spray is varied gradually depending on the required volume fraction of reinforcement to form the gradient structure. Spray cast FGM has very attractive properties owing to the fact that solidification process is very rapid and particle engulfment by the solid is high due to high solidification rates and large shear forces from particles. This results in a fine grained matrix structure and good dispersion of particles.

In the case of liquid metal stir casting, followed by settling or centrifugal casting, the longer holding time at high temperature gives detrimental reaction products at the metal-ceramic interface, whereas comparatively shorter solidification time prevents the formation of significant reaction products in spray casting. The ability to spray form large near-net-shape extrusion/forging preform, tubes, rolls and strips with fine scale microstructures in large cross sections from the melt offers potential economic benefits compared to ingot and powder metallurgy. However, as spray formed preforms always contain some porosity and they must be consolidated to full density by extrusion, rolling or hot isostatic pressing. In the case of FGM, further processing can destroy the gradients in the microstructure.

\subsection{Gradient Slurry Disintegration and Deposition Process}

Gradient slurry disintegration and deposition (GSDD) process has been developed by Nai et al. [35]. For the $\mathrm{Al} / \mathrm{SiC}_{\mathrm{p}} \mathrm{FGM}$ by GSDD, the synthesis procedure involves superheating ultrasonically cleaned aluminium strips to $950{ }^{\circ} \mathrm{C}$ in a graphite crucible. Preheated $\mathrm{SiC}$ particulates (to improve the wettability of the $\mathrm{SiC}_{\mathrm{p}}$ with the matrix material) for an hour at $950{ }^{\circ} \mathrm{C}$, are added to the molten aluminium via a vibratory feeder and stirred with a twin blade Zirtex coated stirrer at about $294 \mathrm{r} /$ min. This stirring speed is chosen so as to allow controlled sedimentation of $\mathrm{SiC}$ particulates. The total addition time of $\mathrm{SiC}$ particulates was limited to a maximum of $15 \mathrm{~min}$, to prevent formation of traceable interfacial reaction products. Following stirring, the FGM melt is poured through a $10 \mathrm{~mm}$ centrally drilled hole at the base of the graphite crucible and the melt slurry is disintegrated using two linear argon gas jets, located at $0.265 \mathrm{~m}$ from the melt pouring point. The argon gas flow rate is maintained at $25 \mathrm{~L} / \mathrm{min}$. The disintegrated melt slurry is then subsequently deposited onto a metallic substrate located at a distance of $0.50 \mathrm{~m}$ from the disintegration point. The solidified FGMs are obtained in the form of ingots with diameter of $40 \mathrm{~mm}$ and lengths varying between 90 and $175 \mathrm{~mm}$. The $\mathrm{SiC}_{\mathrm{p}} / \mathrm{Al}-20 \mathrm{Si}-3$ $\mathrm{Cu}$ FGM was prepared by spray-deposition technique which can meet the structure design requirements of a brake disc by the formation of a gradient distribution of $\mathrm{SiC}$ from 2.86 to $15.21 \mathrm{vol} \%$ along the deposition direction [36].

\subsection{Laser Melt Processing}

In this process, the laser forms a melt pool on the substrate into which metal powder is injected. The injected powder fuses onto the substrate as the laser scans over the part, leaving a bead of deposited material. The material is deposited only where the laser strikes the surface. Since the laser can be positioned accurately, it is easy to selectively deposit material reducing the machining time otherwise in subsequent processing operations.

$\mathrm{SiC}$ particles reinforced $\mathrm{Ti}_{6} \mathrm{Al}_{4} \mathrm{~V}$ FGMs have been fabricated using laser melt injection (LMI) method by Pei et al. [37]. $\mathrm{SiC}_{\mathrm{p}}$ are injected just behind the laser beam into the extended part of the laser melt pool that is formed at relatively high beam scanning velocities. The process allows for the minimisation of the decomposition reaction between $\mathrm{SiC}_{\mathrm{p}}$ and $\mathrm{Ti}_{6} \mathrm{Al}_{4} \mathrm{~V}$ melt, and also leads to $\mathrm{FGMs}$ of $\mathrm{SiC}_{\mathrm{p}} / \mathrm{Ti}_{6} \mathrm{Al}_{4} \mathrm{~V}$ instead of a homogeneous composite layer on $\mathrm{Ti}_{6} \mathrm{Al}_{4} \mathrm{~V}$ substrates. An injection model is designed based on the temperature/viscosity field of the laser pool for a deeper understanding of the mechanism of formation of the FGMs with LMI. The most important factors that dominate the success of the injection process and consequently the properties of the composite layer are the following: (a) particles dissolution and reaction with the matrix melt at high temperatures; (b) distribution and volume fraction of the injected particles and (c) thermal stresses built up in the composite layer during cooling of the melt pool. The key point for the realisation of the injection conditions is to extend the laser pool backwards behind the beam as far as possible, which will provide the necessary space for particles to inject without touching the beam. This is achieved with the aid of relatively high scanning velocities of the beam in combination with appropriate laser powers.

The higher the beam scanning velocity, the steeper is the slope of the profile. The formation of the FGMs is most likely controlled by the laser beam scanning velocity, if the powder stream is strictly focused onto the extended part of the laser pool and the injection velocity of the particles is appropriate.

Direct laser metal deposition process has been used for making continuously graded Stainless Steel 316L and Inconel 718 thin wall structures. The process parameters such as laser power levels and powder mass flow rates of SS316L and Inconel 718 influences the deposition of the Steel-Ni graded structures [38]. 


\section{Solid State and Other Processing Methods}

\subsection{Powder Metallurgy}

The powder metallurgy (PM) is one of the most useful and simplest methods for manufacturing of FGMCC in solid state condition. In this process, a preform of powder containing the desired gradient of reinforcement in metal matrix is first fabricated followed by the conventional solid state densification such as hot pressing in a closed die, hot isostatic pressing or cold pressing and pressureless sintering.

In the solid state process, the densification kinetics of FGMCC is complex in nature due to the variation in densification rate of varying volume fraction of ceramics in metal matrix. At low volume of the ceramics, the densification is controlled by the matrix, whereas at higher volume, the ceramic carries the load and resists the contraction. The various forms of defects observed in FGMCC like warpage, distortion or crack in the sintered bodies are due to the differences in shrinkage and thermal and mechanical properties [39]. The sintering of graded compacts exhibit different behaviours (ranging from elastic to viscous and then come back to elastic) at different stages of sintering depending on material properties like green density, particle size, compositional gradients and geometry.

Graded sintering under ultra-high pressure (GSUHP) was applied to fabricate W/Cu FGM containing $1 \% \mathrm{La}_{2} \mathrm{O}_{3}$ and $1 \% \mathrm{TiC}$ and the specimens exhibit low porosity (11.57\% and $11.35 \%$, respectively) [40]. W/Cu FGM shows good shear strength between layers and good thermal-shock resistance. The specimens with $1 \% \mathrm{La}_{2} \mathrm{O}_{3}$ have not damaged, whereas $1 \%$ TiC containing specimen began to crack when power density of laser is $200 \mathrm{MW} \mathrm{m} \mathrm{m}^{-2}$ and tested for thermal-shock resistance (1,000 times).

\subsection{Slurry Casting}

Centrifugal casting is extensively used for gradation of ceramic powders containing two or more ceramics [41]. In polymer composites, graded structures were obtained by centrifugal casting method. Unlike in solidification of MMCs where the casting and the solidification is of the order of couple of minutes and the gravity-aided segregation effect is marginal, in polymer composites the time for gelling and hardening of the composites is normally an order of magnitude higher than that of MMCs, the gravityaided effect becomes significant. Taking into consideration of these factors also processes have been developed to make FGMs for variety of applications [42].

\subsection{Diffusion Bonding}

This process involves the formation of graded structure by stacking metallic foils of different thickness and numbers with varying volume fraction of ceramic phase followed by diffusion bonding.

\subsection{Vapour Deposition}

FGMCC has been successfully synthesised by vapour deposition process using partially reactive physical vapour deposition, involving combined deposition of one or several vaporised metal elements, with simultaneous introduction of carbon or nitrogen atoms in the gas phase. These react with the depositing metal atoms to form a controlled mixture of the metals and their associated nitrides or carbides. The graded structures are formed by varying the time and concentration of the reactive gas that is introduced. Al-AIN FGMCC coatings have been fabricated by physical vapour deposition of the pure $\mathrm{Al}$ and stepwise or continuous variation in the nitrogen content.

\subsection{Thermal Spray Deposition}

Thermal spray deposition involves feeding of powder particles into a hot zone of a torch, where they are heated, accelerated and deposited on a substrate and rapidly solidified. When the plasma flame is used as the source of energy, it is termed as 'Plasma spray deposition'. In the plasma spray forming, the metal and the ceramic phases are simultaneously melted and blended to the required proportion by controlling their relative feed rates. Twin torch plasma deposition apparatus is advantageous and usually used for processing FGMCC due to the substantial variation in the processing parameters such as distance between the gun and substrate, carrier gas composition and feed rate, arc voltage and current density, and spray chamber atmosphere.

\subsection{Electrodeposition}

Electrodeposition technique has been used for the synthesis of FGMCC coatings by adding ceramic particles to the electrolytic solution and incorporating these particles into the growing metal layer during electrodeposition. The graded layers can be obtained by either varying (a) the current density as a function of time or (b) the volume fraction in the suspension. The volume fraction of incorporated ceramic particles decreases with increasing density. 


\section{Properties}

The major advantage of FGM is its ability to give two conflicting properties in a single component such as good thermal conductivity and good thermal resistance. Space planes require materials with such properties for actively cooling on one side while facing a hot environment on the other side. The metallic side provides good thermal conductivity while the ceramic side gives good thermal resistance.

FGM are ideal for wear-resistant linings in the mineral processing industry since they comprise of a hard ceramic face on the exposed side, a tough metal face on the rear side that can be bolted or welded to a support frame, and a graded composition from metal to ceramic in between. The gradation would enhance the toughness of the ceramic face and also prevent ceramic-metal debonding.

The microstructure and mechanical behaviours including tensile and fracture properties of a functionally gradient Al $\mathrm{A} 359 / \mathrm{SiC}_{\mathrm{p}}$ composite processed by centrifugal casting have been investigated by Rodríguez [21]. The effect of $\mathrm{SiC}$ particulates on strengthening of A359 Al alloy was limited up to a certain volume fraction. There was a continuous increase in tensile and yield strengths with $\mathrm{SiC}$ volume fractions in the range of $0.20-0.30$ obtained in the $700 \mathrm{r} / \mathrm{min}$ cast composite. On the contrary, there was a reduction in tensile and yield strength for $\mathrm{SiC}$ concentrations in the range of $0.30-0.40$ obtained in the $1,300 \mathrm{r} / \mathrm{min}$ composite. The constant $0.20 \mathrm{SiC}$ volume fraction composite showed an improvement in tensile strength, but this was limited to the region in which the high cooling rate promoted a uniform distribution of reinforcement. The elastic modulus obtained in the whole reinforcement range (20\%-40\%) was according to predictions by the self-consistent method [43], i.e. a gradual increase in stiffness was observed at increasing $\mathrm{SiC}$ volume fractions.

Figure 13 show the macro-photograph and properties of the brake rotor disc. The volume fraction of $\mathrm{SiC}$ distribution from outer to inner periphery was measured by image analysis (Fig. 13b). Higher fraction of particle is observed in the braking outer region of the disc, which in turn enhanced the hardness of the disc towards the outer periphery (Fig. 13c) [44]. The tensile strength, elastic modulus and compression strength are higher towards the outer periphery of the component. Figure 14 shows macrophotograph of as cast cylinder liner fabricated using A390 aluminium alloy, the volume fraction of primary silicon from inner to outer periphery and hardness profile of the cylinder liner from outer to inner periphery [45]. The higher concentration of primary particles towards the inner periphery enhanced the hardness towards the inner region. Evaluation on disc and cylinder liner clearly demonstrates the formation of graded properties within a component obtained by centrifugal casting. Depending upon the matrix alloy used the pattern of microstructural gradation gets changed due to the different solidification characteristics. Studies on SiC reinforced FGMMC using 356 and 2124 matrix alloys show different microstructural patterns [46]. The addition of magnesium in A390 alloy from 3 to $5 \mathrm{wt} \%$ Mg using Al-20 Mg master alloy has shown a transformation from primary silicon-rich matrix to $\mathrm{Mg}_{2} \mathrm{Si}$-rich matrix. Centrifugal casting shows the gradient distribution of primary silicon and $\mathrm{Mg}_{2} \mathrm{Si}$ phases towards the inner periphery of the casting [47].

\section{General Discussion}

This paper describes the concept of functionally gradient materials and presents the processing methods of functionally graded metals and metal-ceramic composites. Among the various processing methods available, ones based on solidification route are preferred owing to their economics and capability to make large size products. In common during the formation of a graded structure, the transition from one phase/constituent to the other leads to a multiphase/ composite system. Hence, majority of the graded structures are composite systems containing varying volume fraction of the constituent phases from one position to other. Therefore, processing of these inhomogeneous graded structures using existing processing methods for conventional alloys and homogenous composites pose difficulties in applying it directly. However, various investigations on the processing of FGMCC show that existing methods have been successfully adopted after modification in the processing parameters or by introducing some major changes to the existing techniques. For example, the infiltration process has been successfully used by infiltration of liquid metal through a graded perform instead of homogenous perform. Similarly, the spray casting technique has been adopted by changing the feed rate of reinforcement gradually into the atomized stream of liquid metal to produce the graded composite. On the other hand, centrifugal casting technique has been used for the processing of MMC leading to a graded structure, even before the concept of FGM is introduced.

In general, the processing methods of FGMCC have been classified as solid phase, liquid phase and deposition techniques. Most of the solidification techniques fall under the category of liquid phase techniques except the deposition techniques such as spray casting and laser melt injection. Centrifugal casting and gravity settling methods are more economic than other methods and are widely used. However, for using wide variety of reinforcement with large volume fraction range and selective reinforcement and graded structure formation the infiltration methods are ideal. In some cases, the centrifugal force is applied 


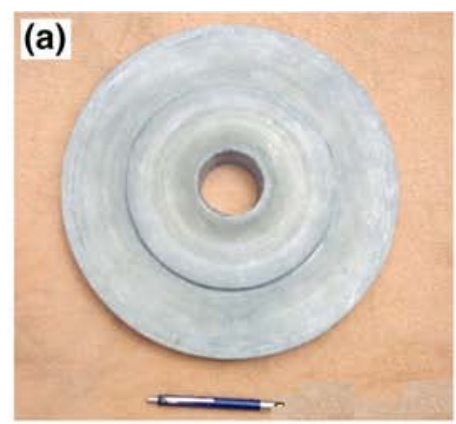

(d)

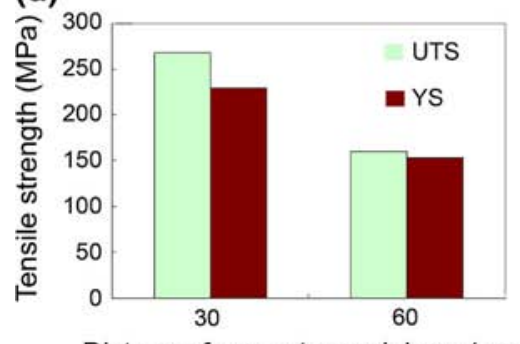

Distance from outer periphery $(\mathrm{mm})$
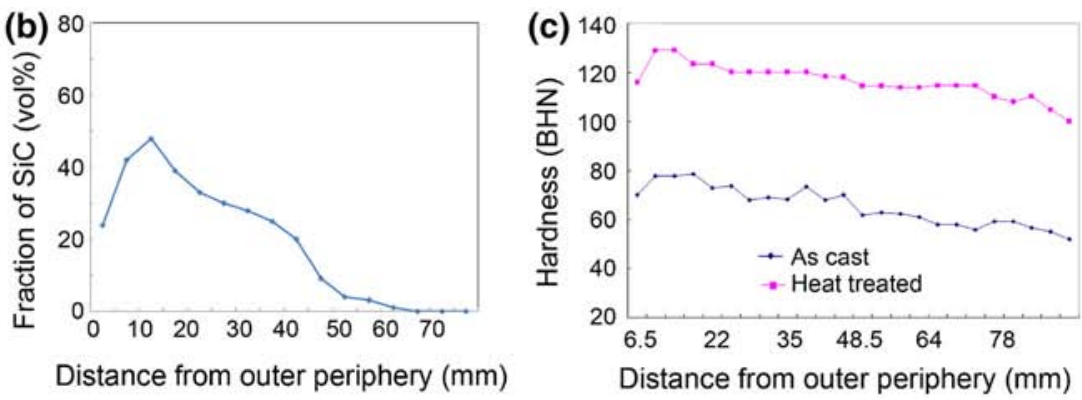

(e)

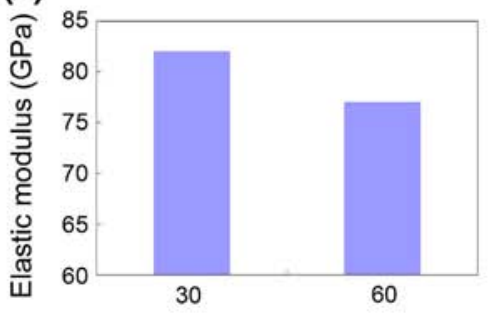

Distance from outer periphery $(\mathrm{mm})$

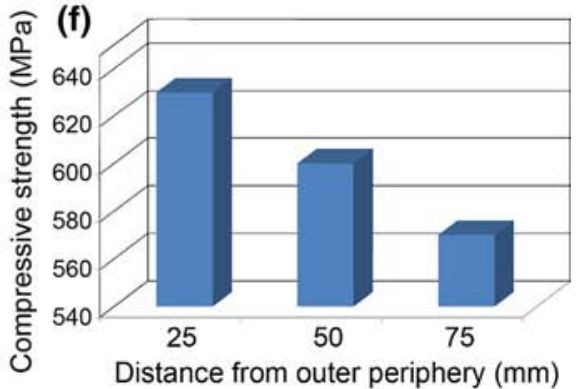

Fig. 13 Macrograph and properties of the brake rotor disc: $\mathbf{a}$ macrograph; $\mathbf{b}$ volume fraction of $\mathrm{SiC}$ distribution from outer to inner periphery by image analysis; $\mathbf{c}$ hardness profile; $\mathbf{d}$ tensile strength; $\mathbf{e}$ modulus of elasticity; $\mathbf{f}$ compression strength
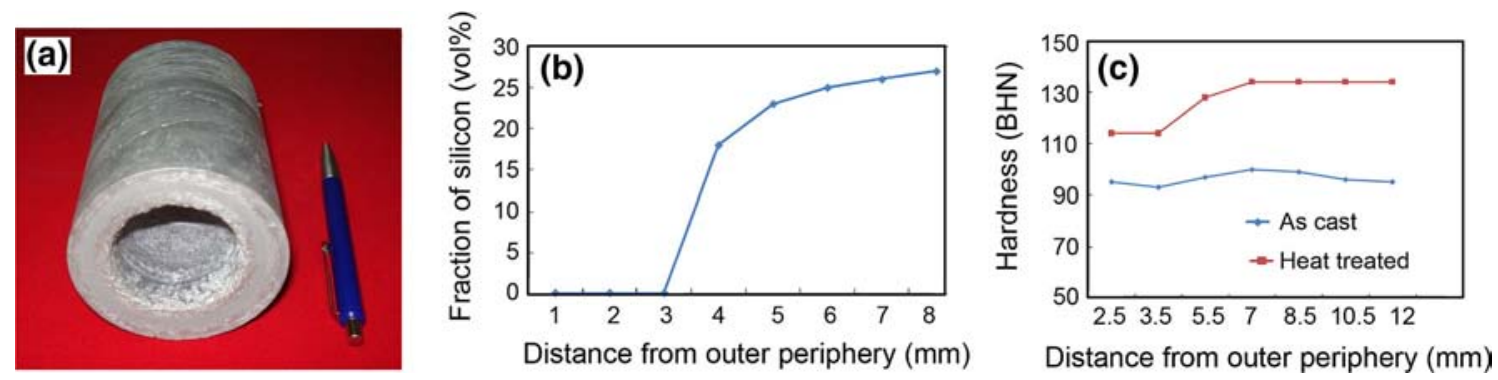

Fig. 14 a Macrograph of as cast cylinder liner fabricated using Al390 aluminium alloy; b volume fraction of primary silicon from inner to outer periphery; $\mathbf{c}$ hardness profile of the cylinder liner from outer to inner periphery

to infiltrate the liquid metal into a graded perform. Here, both the processes are coupled to produce a functionally graded component. Spray casting technique has been used to produce near-net-shape components as well bulk preform materials for extrusion, forging and rolling. Better dispersion of reinforcements and fine microstructure as well as lower interfacial reaction can be achieved by spray casting. Laser melt processing is useful in making graded structure on already fabricated components in very fine level and selectively.

The functionally graded concept of material processing can be applied more widely by adopting the inverse design and analysis technique in the existing as well as in newly developed components and structures. The unnecessary use of homogenous composite material just to obtain a specific property in selected area of a bulk component can be evaded by the use of FGM.

\section{Applications}

FGMCC finds wide applications in the area where the operating conditions are severe. For example, wear-resistant linings for handling heavy abrasive ore particles, rocket heat shields, heat exchanger tubes, thermoelectric generators, heat-engine components, plasma facings for fusion reactors and electrically insulating metal/ceramic joints. They are also ideal for minimising thermomechanical mismatch in metal-ceramic bonding.

One of the applications of FGMs is to thermal barrier coatings (TBCs). For example, the use of thermal barriertype FGM coatings in advanced gas turbines offers a reduction in fuel consumption by allowing much less flow of coolant or higher turbine inlet temperature, while improving durability by decreasing base metal temperature. The major problem in the use of a TBC on a metal substrate is the 

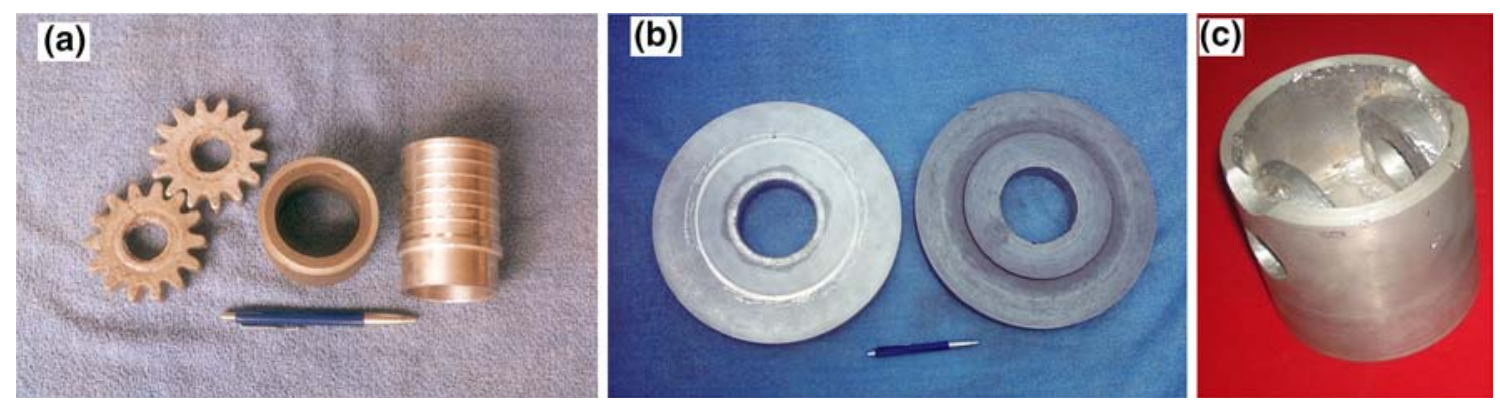

Fig. 15 Functionally graded aluminium-matrix composite prototype components: a cylinder liners and gears; b brake rotor disc; c piston fabricated by centrifugal casting for engineering application at NIIST

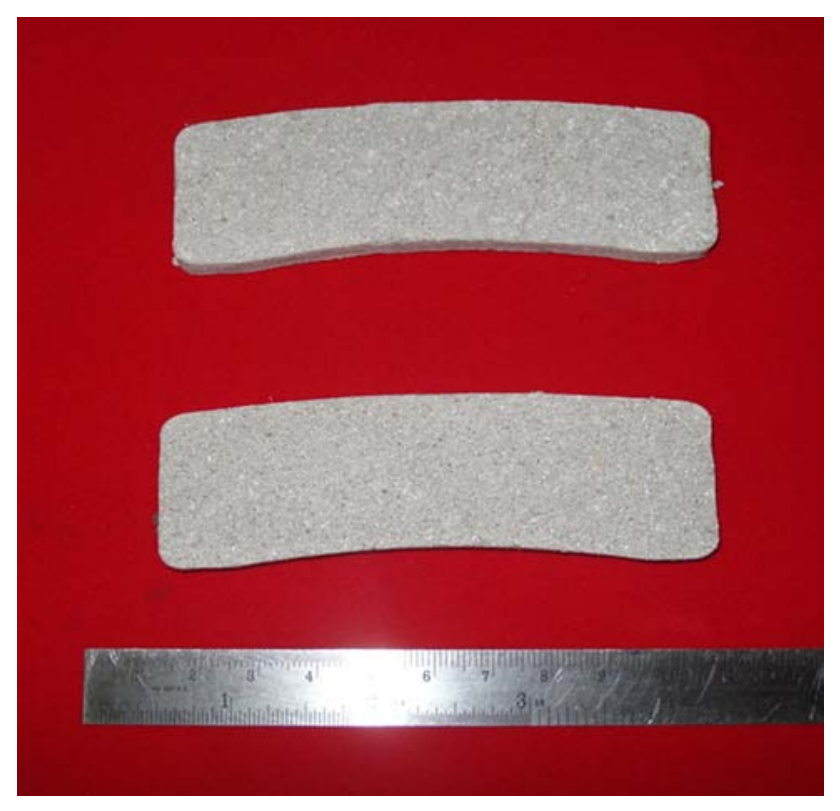

Fig. 16 Functionally graded metal-ceramic brake pads developed by NIIST using squeeze infiltration

spalling of the ceramic coating due to the large thermal stresses produced during the thermal cycling in an oxidation environment. The thermal stresses are induced mainly by the thermal expansion mismatch between a ceramic coating and a metal bond coat as well as the temperature gradient within the coating and the substrate. The introduction of a functionally graded structure into the coating improves the resistance of the TBC to thermal shock cracking, because the FGM structure is capable of effectively reducing the thermal stresses, which are generated at the interface between a ceramic coating and a metal substrate.

There is vast potential for the development of new functionally graded composites for various applications. Since the FGMs are produced to achieve a certain property requirement in particular positions of a component, it is better to work out an inverse design in developing the FGMs for the specific application or component. The existing components made of homogenous materials can be replaced by FGM, where it can improve the performance and be economical.
Fabrication of functionally graded components by centrifugal casting method has wide scope for different engineering applications. Figure 15 shows few functionally graded aluminium-matrix composite prototype components fabricated by centrifugal casting for engineering application at the National Institute for Interdisciplinary Science and Technology, Trivandrum. Various prototype FGM components such as cylinder liners and gears, brake rotor disc and piston had been fabricated by centrifugal casting technique. Al-SiC FGM fishing boat cable pulleys are reported to be fabricated successfully by centrifugal casting method. The hybrid composite cylinder liners prepared for two wheelers' applications have shown (Fig. 15a for component, Fig. 9 for microstructure) both excellent abrasive and adhesive wear resistance in the prototype component evaluation test due to the presence of both hard $\mathrm{SiC}$ and soft graphite particles together in the inner periphery of the castings [46]. Centrifugal casting has been applied to develop clutch drums composed of hard TiC particles embedded in aluminium bronze matrix for naval applications. The lighter TiC particles, initially suspended in the heavier molten bronze, migrate to the centre during centrifugal casting, producing a carbide-rich inner surface that is highly abrasion resistant. Selectively reinforced casting MMC Powertrain Components have been developed by the Pacific Northwest National Laboratories for the automotive sector using centrifugal casting. Figure 16 shows the prototype functionally graded metal-ceramic brake pads developed by NIIST using squeeze infiltration techniques. This component is a stepwise graded system containing mainly the aluminosilicate fibres, $\mathrm{SiC}$ and graphite particles. Engineering components requiring functionally graded properties can be identified, designed and fabricated through the centrifugal casting techniques.

\section{Conclusions}

FGMCC are becoming one of the potential advanced materials for new technologies, where a single component 
warranting two contradicting properties. Many techniques such as powder metallurgy, diffusion bonding, infiltration, settling, centrifugal casting, vapour deposition, thermal spray process and electrodeposition have been successfully used for their fabrication. However, those based on solidification route are preferred for their economics and capability to make large size components. Similarly, the solidification processing methods such as infiltration, centrifugal casting and spray casting used for producing homogenous MMC can be extended to FGMCC by varying the process parameters or by little modification in the technique. Since the FGMs are produced to achieve a certain property requirement in particular positions of a component, it is better to work out an inverse design in developing the functionally gradient materials for the specific application or component. There is vast potential for the development of new functionally graded composites as well as new processing methods. As the processing parameters vary from system to system, there is a wide scope to optimise these parameters.

Acknowledgments The authors would like to thank the Director, CSIR-NIIST and members, MSTD for their support and encouragement. We are grateful to the research scholars Mr. E. Jayakumar, Mr. K. M. Sree Manu and Mr. Akhil S. Karun for their contribution towards the preparation of manuscript and the CSIR, New Delhi towards the funding.

\section{References}

[1] M. Niino, S. Maeda, ISIJ Int. 30, 699 (1990)

[2] A. Mortensen, S. Suresh, Int. Mater. Rev. 40(6), 239 (1995)

[3] S. Suresh, A. Mortensen, Int. Mater. Rev. 42(3), 85 (1997)

[4] J.J. Sobczak, L. Drenchev, J. Mater. Sci. Technol. 29, 297 (2013)

[5] E. Arzt, M.F. Ashby, K.E. Eastreling, Metall. Trans. A 14, 211 (1983)

[6] W. Henning, C. Melzer, S. Mielke, Metallurgy 46, 436 (1992)

[7] S.F. Corbin, X. Zhao-jie, H. Henein, P.S. Apte, Mater. Sci. Eng., A 262, 192 (1999)

[8] P. Zhao, S.B. Guo, G.H. Liu, Y.X. Chen, J.T. Li, J. Alloys Compd. 601, 289 (2014)

[9] A. Nordmark, Stoberiet 69(7), 6 (1992)

[10] L. Lajoye, M. Suery, in International Symposium on "Advances in cast reinforced metal composites", Chicago, IL, 1988, ed. by S.G. Fishman, A.K. Dhingra (ASM International, Materials Park, OH, 1988) pp. 15-20

[11] L. Lajoye, M. Suery, in Solidification Processing 1987, ed. by J. Beech, H. Jones (The Institute of Metals, 1988) p. 443

[12] G.S. Hanumanth, G.A. Irons, S. Lafreniere, Metall. Trans. B 23, 753 (1992)

[13] G.A. Rons, K. Owusu-Boahen, Metall. Trans. B 26, 981 (1995)

[14] M. Pourmajidian, F. Akhlaghi, J. Mater. Eng. Perform. 23, 444 (2014)

[15] P. Diouf, A. Jones, Metall. Mater. Trans. A 41, 603 (2010)

[16] X.H. Qin, L.X. Han, C.G. Fan, L.J. Rong, Y.Y. Li, J. Mater. Sci. Lett. 21, 665 (2002)

[17] G. Chirita, I. Stefanescu, J. Barbosa, H. Puga, D. Soares, F.S. Silva, Int. J. Cast Met. Res. 22, 382 (2009)
[18] B.P. Krishnan, P.K. Rohatgi, Metall. Technol. 11, 41 (1984)

[19] A. Baneerji, P.K. Rohatgi, W. Reif, in Proceedings of Europe MRS Conference Advanced Materials Research and development of Transportation of Composites (Strassburg, France, 1985)

[20] A. Velhinho, P.D. Sequeira, R. Martins, G. Vignoles, F. Braz Fernandes, J.D. Botas, L.A. Rocha, Nucl. Inst. Methods Phys. Res. B 200, 295 (2003)

[21] R. Rodríguez-Castro, R.C. Wetherhold, M.H. Kelestemur, Mater. Sci. Eng., A 323, 445 (2002)

[22] T.P.D. Rajan, R.M. Pillai, B.C. Pai, in Proceedings of 3rd International Conference on Materials Processing for Properties and Performance, Singapore, 24-26 November 2004, ed. by K.A. Khor (Institute of Materials (East Asia), Singapore, 2004) p. 33

[23] K. Durai Babu, Dissertation, CSIR-National Institute for Interdisciplinary Science and Technology, Trivandrum, India, 2005

[24] B.A. Srinivasan, Dissertation, CSIR-National Institute for Interdisciplinary Science and Technology, Trivandrum, India, 2006

[25] T.P.D. Rajan, R.M. Pillai, B.C. Pai, J. Alloys Compd. 453, L4 (2008)

[26] Y. Fukui, K. Takashima, C.B. Panton, J. Mater. Sci. 29, 2281 (1994)

[27] Y. Watanabe, S. Oike, Acta Mater. 53, 1631 (2005)

[28] Y. Watanabe, N. Yamanaka, Y. Fukui, Metall. Mater. Trans. A 30, 3253 (1999)

[29] Y. Watanabe, H. Eryu, K. Matsuura, Acta Mater. 49, 775 (2001)

[30] Z. Humberto Melgarejo, O. Marcelo Suárez, K. Sridharan, Scr. Mater. 55, 95 (2006)

[31] Y. Watanabe, T. Nakamura, Intermetallics 9, 33 (2001)

[32] J. Zhang, Z. Fan, Y. Wang, B. Zhou, Mater. Des. 21, 149 (2000)

[33] D.R. Herling, W.H. Hunt, Low-cost cast aluminum metal matrix composites have arrived, in Affordable Metal Matrix Composites for High Performance Applications II (Minerals, Metals \& Materials Society, Warrendale, Pennsylvania, 2004) pp. 13-23

[34] P.S. Grant, Prog. Mater Sci. 39, 497 (1995)

[35] S.M.L. Nai, M. Gupta, C.Y.H. Lim, Compos. Sci. Technol. 63, 1 (2003)

[36] B. Su, H.G. Yan, J.H. Chen, P.L. Zeng, G. Chen, C.C. Chen, J. Mater. Eng. Perform. 22, 1355 (2013)

[37] Y.T. Pei, V. Ocelik, JThM De Hosson, Acta Mater. 50, 2035 (2002)

[38] K. Shah, I. Haq, A. Khan, S.A. Shah, M. Khan, A.J. Pinkerton, Mater. Des. 54, 531 (2014)

[39] B.S. Zhang, M.M. Gasik, Comput. Mater. Sci. 25, 264 (2002)

[40] K. Zhang, W.P. Shen, C.C. Ge, Acta Metall. Sin. (Engl. Lett.) 20, 59 (2007)

[41] S. Maleksaeediw, M.H. Paydar, J. Am. Ceram. Soc. 93, 413 (2010)

[42] J. Stabik, A. Dybowska, M. Chomiak, J. Ach, Mater. Manuf. Eng. 43, 153 (2010)

[43] S.F. Corbin, D.S. Wilkinson, Acta Metall. Mater. 42, 1311 (1994)

[44] T.P.D. Rajan, R.M. Pillai, B.C. Pai, Int. J. Cast Met. Res. 21(1-4), 214 (2008)

[45] T.P.D. Rajan, R.M. Pillai, B.C. Pai, Mater. Charact. 61, 923 (2010)

[46] E. Jayakumar, T.P.D. Rajan, B.C. Pai, Trans. Ind. Inst. Met. 65, 681 (2012)

[47] T.P.D. Rajan, R.M. Pillai, B.C. Pai, A Method for Processing Functionally Graded Hybrid Metal Matrix Composites, Indian Patent 0903DEL2006, 2006 